\title{
Laparoscopic complete mesocolic excision with central vascular ligation for splenic flexure colon cancer: short- and long-term outcomes
}

\author{
Kazuki Ueda ${ }^{1}\left[\right.$ - Koji Daito ${ }^{1} \cdot$ Hokuto Ushijima ${ }^{1}$. Yoshinori Yane ${ }^{1}$. Yasumasa Yoshioka ${ }^{1} \cdot$ Tadao Tokoro $^{1}$. \\ Masayoshi Iwamoto ${ }^{1} \cdot$ Toshiaki Wada $^{1} \cdot$ Yusuke Makutani ${ }^{1} \cdot$ Junichiro Kawamura $^{1}$
}

Received: 17 September 2020 / Accepted: 11 May 2021 / Published online: 24 May 2021

(c) The Author(s) 2021

\begin{abstract}
Background Complete mesocolic excision (CME) with central vascular ligation (CVL) for colon cancer is an essential procedure for improved oncologic outcomes after surgery. Laparoscopic surgery for splenic flexure colon cancer was recently adopted due to a greater understanding of surgical anatomy and improvements in surgical techniques and innovative surgical devices.

Methods We retrospectively analyzed the data of patients with splenic flexure colon cancer who underwent laparoscopic CME with CVL at our institution between January 2005 and December 2017.

Results Forty-five patients (4.8\%) were enrolled in this study. Laparoscopic CME with CVL was successfully performed in all patients. The median operative time was $178 \mathrm{~min}$, and the median estimated blood loss was $20 \mathrm{~g}$. Perioperative complications developed in 6 patients (13.3\%). The median postoperative hospital stay was 9 days. According to the pathological report, the median number of harvested lymph nodes was 15 , and lymph node metastasis developed in 14 patients (31.1\%). No metastasis was observed at the root of the middle colic artery or the inferior mesenteric artery. The median follow-up period was 49 months. The cumulative 5-year overall survival and disease-free survival rates were $85.9 \%$ and $84.7 \%$, respectively. The cancer-specific survival rate in stage I-III patients was $92.7 \%$. Recurrence was observed in 5 patients (11.1\%), including three patients with peritoneal dissemination and two patients with distant metastasis.

Conclusions Laparoscopic CME with CVL for splenic flexure colon cancer appears to be oncologically safe and feasible based on the short- and long-term outcomes in our study. However, it is careful to introduce this procedure to necessitate the anatomical understandings and surgeon's skill. The appropriate indications must be established with more case registries because our experience is limited.
\end{abstract}

Keywords Colorectal surgery $\cdot$ Laparoscopic surgery $\cdot$ Splenic flexure $\cdot$ Surgical outcome $\cdot$ Transverse colon cancer · Descending colon cancer

The safety and benefits of laparoscopic surgery for colorectal cancer have been demonstrated and confirmed by several randomized controlled trials (RCTs) and meta-analyses [1-4]. In Japan, the Japan Clinical Oncology Group (JCOG) 0404 also conducted an RCT to establish the noninferiority of laparoscopic surgery to open D3 surgery for stage II or III

Kazuki Ueda

ueda-k@med.kindai.ac.jp

1 Department of Surgery, Kindai University

Faculty of Medicine, 377-2, Ohnohigashi,

Osaka Sayama, Osaka 589-8511, Japan colon cancer [5]. The short-term outcomes were the safety and clinical benefits of laparoscopic surgery, as shown in a previous RCT [6]. Concerning survival outcomes, patients who underwent laparoscopic surgery had a relatively high overall survival rate, which was better than expected [7]. Since its equivalence to open surgery has become apparent, laparoscopic surgery has been widely accepted as a standard strategy for colorectal malignancies.

Complete mesocolic excision (CME) with central vascular ligation (CVL) for colon cancer was introduced by Hohenberger and has improved oncologic outcomes after surgery [8-10]. This concept of CME with CVL for colon cancer is to extract the tumor in its entirety, with free 
margins of the bowel and mesocolon, and including lymphatic spread along the supplying vessels at its origin; this concept is similar to that of total mesorectal excision (TME) for rectal cancer described by Heald et al. [11]. Although the extent of longitudinal resection differs in Europe and Japan and is still debatable, the Japanese surgeons follow the concept that is known as D3 lymph node dissection, advocated by the Japanese Society for Cancer of the Colon and Rectum (JSCCR) guidelines [12, 13].

Transverse colon and descending colon cancers were excluded from the majority of previous prospective studies because of complex anatomy, technical difficulties, and difficulty in judging the related central vessels and regional lymph nodes. Since several decades have passed since the first described laparoscopic colectomy [14], with a better understanding of surgical anatomy and improvements in laparoscopic surgical techniques and innovative surgical devices, laparoscopic surgery for splenic flexure colon cancer was recently adopted $[15,16]$.

This retrospective study aimed to evaluate the short- and long-term outcomes of laparoscopic resection for splenic flexure colon cancer in our single institution.

\section{Materials and methods}

\section{Patients}

We retrospectively analyzed a total of 938 patients who underwent laparoscopic colectomy for colorectal cancer at Kindai University Hospital between January 2005 and December 2017 from our prospectively collected database. Splenic flexure colon cancer was defined as a tumor located between the distal third of the transverse colon and the first proximal portion of the descending colon within $10 \mathrm{~cm}$ of the splenic flexure. During the study periods, 45 consecutive patients (4.8\%) who underwent laparoscopic curative resection for pathologically proven primary colon adenocarcinoma were reviewed retrospectively. Our exclusion criteria for laparoscopic surgery were as follows: bulky tumor invasion to adjacent organs (stage T4b), apparent lymph node metastasis in the root of the inferior mesenteric artery or para-aorta, emergency surgery for bowel obstruction and/ or perforation due to the tumor and synchronous unresectable multiple liver metastases. In patients with altered colon anatomy due to previous colorectal surgery, an open procedure was also adopted.

All the patients underwent preoperative total colonoscopy and plane- or contrast-enhanced computed tomography (CT) to determine the exact tumor location and to detect distant metastases. The feeding artery to the tumor was also confirmed by three-dimensional (3D) CT imaging when possible. Histology was confirmed by endoscopic biopsy prior to surgery for all patients.

The disease stage was evaluated according to the American Joint Committee on Cancer Staging, $8^{\text {th }}$ Edition.

This study was approved by the Institutional Review Board of the Kindai University Faculty of Medicine. Due to the retrospective nature of the study, written informed consent was not obtained. We used the opt-out approach to disclose the study information.

\section{Surgical procedure}

Oncological surgical resection was performed as described in the JSCCR guidelines [12]. All laparoscopic surgeries were performed by surgeons who passed the skill accreditation system for laparoscopic gastrointestinal surgery, established by the Japanese Society for Endoscopic Surgery (JSES). All cases were performed only by three highly skilled laparoscopic colorectal surgeons.

Under general anesthesia, the patient was placed in the supine position in the modified lithotomy position using stirrups. Both arms were alongside the body. The first camera trocar $(12 \mathrm{~mm})$ was inserted at $3.5 \mathrm{~cm}$ of the umbilical incision via a round-shaped E.Z ACCESS with LAP PROTECTOR MINI device (Hakko Co., Ltd., Tokyo, Japan). Pneumoperitoneum was established (up to $8 \mathrm{mmHg}$ ) with carbon dioxide through the camera trocar. Four additional 5-mm trocars were inserted in an inverted trapezoid shape under direct vision around the umbilical lesion. The omentum and transverse colon were moved toward the upper abdomen. A medial-to-lateral approach was utilized for this procedure. CME was performed with careful mobilization of colonic mesentery avoiding mesenteric injury, and CVL was performed following a preoperative $\mathrm{CT}$ scan with regard to the correlation between the tumor and supplying/drainage vessels. In the case of T3 or T4 tumors, partial omentectomy around the tumor was performed. The transverse mesentery was dissected at the lower border of the pancreas. The splenic flexure was fully mobilized with a securely preserved pancreas and spleen before anastomosis. The tumor-bearing segment was extracted through umbilical mini-laparotomy. The reconstruction was made by functional end-to-end anastomosis (FEEA), the triangulating stapling technique (TST), or the double stapling technique (DST). The procedure of FEEA was as follows: the bowel was fully mobilized, and the mesentery was divided at the proposed lines of resection. The antimesenteric borders of both bowels were sutured by a single suture. Then, $1-\mathrm{cm}$ enterotomies were made within the segment to be resected $1 \mathrm{~cm}$ beyond the site of vascular division. A side-to-side anastomosis was made using the linear cutting stapler (proximate ${ }^{\circledR}$ linear cutter, TLC75; Ethicon Endosurgery, Cincinnati, OH, USA). After the linear cutting stapler was withdrawn, both bowel ends were 
transected just beyond the enterotomy with the linear cutting stapler [17, 18]. The procedure of TST was also as follows: Three times of the TA ${ }^{\mathrm{TM}} 55$ (Medtronoc, Minneapolis, MN, USA) was used to staple the approximated bowel ends. This technique was an alternative procedure performed by the hand-sewn technique. The important thing is that each stapled line was overlapped to reinforce the anastomosis [19, 20]. The procedure of DST was performed the conventional fashion same as sigmoidectomy or anterior resection.

\section{Surveillance after surgery}

All patients were followed under the JSCCR guidelines 2019 [12]. As described in the guidelines, all patients were followed up for 5 years after surgery. The patients were observed regularly by surgeons every 3 months for the first 3 years and then every $4-6$ months for the next 2 years. The physical examinations and blood tests were done at each visit. Chest and abdominal CT scans were done every 6 months. A colonoscopy was done every 2 years. If metastasis or recurrence was suspected, more detailed diagnostic examinations were performed.

\section{Measured outcomes}

The following variables were measured: patient demographics, intra- and postoperative data, and complications according to the Clavien-Dindo classification [21]. Overall survival, cancer-specific survival, rate of recurrence, and site of recurrence were also analyzed during the follow-up period.

\section{Statistical analysis}

Data are presented as the median and range based on their distribution. Survival analysis was performed using the Kaplan-Meier method. JMP Pro software ver. 15 (SAS Institute Inc., Cary, NC, USA) was used for statistical analysis.

\section{Results}

During the study period, 45 consecutive patients (4.8\%) who underwent laparoscopic curative resection for pathologically proven splenic colon cancer were analyzed. There were 20 men and 25 women ranging in age from 39 to 89 years, with a median age of 71 years. The tumor location included the transverse colon in 31 patients and the descending colon in 14 patients. The patient demographics are shown in Table 1.

The median operative time was 178 min (range, 102-433 min.). The median estimated blood loss was $20 \mathrm{~g}$ (range, 5-946 g). There were four intraoperative complications: two splenic injuries, one pancreatic injury, and one bowel injury. A soft coagulation system was used to
Table 1 Patients' preoperative characteristics

\begin{tabular}{lll}
\hline & \multicolumn{2}{l}{ All patients $(\mathrm{n}=45)$} \\
\hline Age (median [range], y.o.) & 71 & [39-89] \\
Gender (Male/Female) (no.) & $20 / 25$ & \\
BMI (median [range], kg/m²) & 21.8 & \\
Tumor location (T/D, no.) & $31 / 14$ & \\
ASA classification (no.) & & \\
1 & 2 & \\
2 & 33 & \\
3 & 10 & \\
4 & 0 & $(2.2)$ \\
Stage (no., (\%)) & & $(20.0)$ \\
0 & 1 & $(44.4)$ \\
I & 9 & $(28.9)$ \\
II & 20 & $(4.4)$ \\
III & 13 & \\
IV & 2 & \\
\hline
\end{tabular}

$B M I$ body mass index, $T$ transverse colon, $D$ descending colon, $A S A$, the American Society of Anesthesiologists

resolve bleeding from the splenic injuries. However, pancreatic injury was necessitated distal pancreatectomy without requiring conversion to an open procedure. Two patients (4.4\%) required conversion: one for bowel injury and one for the difficulty of visibility due to severe obesity. All patients successfully underwent CME with CVL. Bowel reconstruction was performed for 34 patients via FEEA, 10 patients via the TST, and one patient via the DST. The postoperative recovery course of patients, including the median time to ambulation, flatus, and soft diet intake, was one day (range, 1-3 days), two days (range, 0-4 days), and four days (range, 1-10 days), respectively. The median postoperative hospital stay was nine days (range, 6-227 days). Intra- and postoperative outcomes are shown in Table 2.

Postoperative complications (Clavien-Dindo classification $\geq$ grade 2 ) developed in six patients (13.3\%): anastomotic leakage in one, duodenal stenosis in one, paralytic ileus in two, aspiration pneumonia in one, and surgical site infection in one. Major anastomotic leakage developed in one patient who had undergone emergency surgery in which a diverting stoma was temporarily created. The patient necessitated a long-term admission period and died 289 days postoperatively because of septic shock with chronic heart failure. A ventral hernia developed in two patients as a late complication. One of these patients underwent laparoscopic ventral hernia repair 6 months after primary surgery.

The median tumor size was $35 \mathrm{~mm}$ (range, 5-65 mm). The median number of harvested lymph nodes was 15 (range, 6-56) (Table 2). Lymph node dissection was performed according to the preoperative 3D-CT images and clinical stage. Lymph nodes located at the root of the middle 
Table 2 Operative and postoperative clinicopathological characteristics

\begin{tabular}{|c|c|c|}
\hline \multirow[b]{2}{*}{ Operative time (median [range], min) } & \multicolumn{2}{|c|}{$\begin{array}{l}\text { All patients } \\
(\mathrm{n}=45)\end{array}$} \\
\hline & 178 & {$[102-433]$} \\
\hline Estimated blood loss (median [range], g) & 20 & {$[5-946]$} \\
\hline \multicolumn{3}{|l|}{ Anastomosis } \\
\hline FEEA/TST/DST (no.) & \multicolumn{2}{|c|}{$34 / 10 / 1$} \\
\hline Intraoperative complications (no., \%) & 4 & $(8.9)$ \\
\hline Conversions (no., \%) & 2 & $(4.4)$ \\
\hline \multicolumn{3}{|l|}{ Specimen } \\
\hline Tumor size (median [range], mm) & 35 & {$[5-65]$} \\
\hline \multicolumn{3}{|l|}{ Tumor differentiation } \\
\hline Well or moderately differentiated (no., \%) & 43 & $(95.6)$ \\
\hline Poorly differentiated or mucinous (no., \%) & 2 & $(4.4)$ \\
\hline Harvested nodes (median [range], no.) & 15 & {$[6-56]$} \\
\hline Proximal margin (median [range], mm) & 80 & {$[30-180]$} \\
\hline Distal margin (median [range], mm) & 110 & {$[50-400]$} \\
\hline \multicolumn{3}{|l|}{ Postoperative course } \\
\hline Ambulation (median [range], days) & 1 & {$[1-3]$} \\
\hline Flatus (median [range], days) & 2 & {$[0-4]$} \\
\hline Oral intake (median [range], days) & 4 & {$[1-10]$} \\
\hline $\begin{array}{l}\text { Postoperative length of stay (median [range], } \\
\text { days) }\end{array}$ & 9 & {$[6-227]$} \\
\hline $\begin{array}{l}\text { Postoperative complications }(\mathrm{CD} \geq \text { grade } 2 \text { ) } \\
\text { (no., \%) }\end{array}$ & 6 & $(13.3)$ \\
\hline Anastomotic leakage (no., \%) & 1 & $(2.2)$ \\
\hline Recurrence (no., \%) & 5 & $(11.1)$ \\
\hline Follow-up (median [range], months) & 48.9 & {$[4-174.8]$} \\
\hline Death (no., \%) & 6 & (13.3) \\
\hline
\end{tabular}

FEEA functional end-to-end anastomosis, TST triangulating stapling technique, $D S T$ double stapling technique, $C D$ Clavien-Dindo classification

colic and the inferior artery were dissected in patients with clinical stage II or III disease. Lymph node metastasis developed in 14 (31.1\%) of the 45 patients. The distribution of lymph node metastasis is shown in Fig. 1. No metastasis was observed histologically at the root of the middle colic artery or the inferior mesenteric artery.

The median follow-up period was 49 months (range, 4-175 months). The cumulative 5-year overall survival rate in patients with stage I-III disease was $85.9 \%$, and the 5-year disease-free survival rate was $84.7 \%$. The 5 -year cancerspecific survival rate in patients with stage I-III disease was 92.7\% (Fig. 2). Recurrence was observed in five patients $(11.1 \%)$. The distributions of patients who experienced recurrence are shown in Table 3. Three of five patients experienced peritoneal dissemination: one patient with stage T4a disease and two patients with stage T3 disease. The other two patients developed distant metastases. Local recurrence was not observed during the follow-up period.

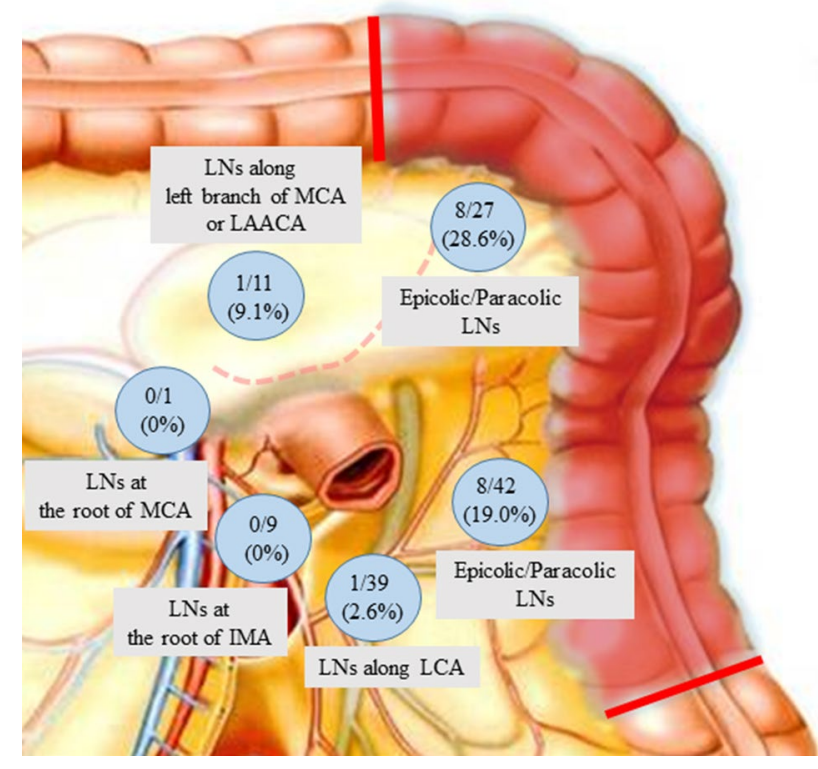

Fig. 1 Distribution of lymph node metastasis in 45 patients who underwent curative resection for splenic flexure colon cancer. $L N s$ lymph nodes, $M C A$ middle colic artery; $L A A C A$ left accessory aberrant colic artery, $L C A$ left colic artery, IMA inferior mesenteric artery

\section{Discussion}

Splenic flexure colon cancer located in the distal transverse colon and the proximal descending colon accounts for approximately $2-5 \%$ of all colorectal cancers [22-25]. The definition of splenic flexure colon cancer is diverse. In this study, splenic flexure colon cancer was defined as a tumor located between the distal third of the transverse colon and the first proximal portion of the descending colon within $10 \mathrm{~cm}$ of the splenic flexure. Following this definition, the incidence of splenic flexure colon cancer in the current study was $4.8 \%$ of the patients presenting with all colon cancers in our institution.

In our institution, laparoscopic colorectal surgery was first introduced in 1995, and its indications have been expanded by the technical level of proficiency. After standardizing the procedure, it has been adopted for splenic flexure colon cancer since 2005. The indications for surgical resection margins and lymphadenectomy were based on the JSCCR guidelines. Although the definition of splenic flexure colon cancer and the surgical procedure for splenic colon cancer are diverse, our short-term outcomes were acceptable according to previous reports (Table 4) [26-32].

As in all colon cancer surgeries, a correct CME procedure, which includes sharp dissection along the embryological planes and obtaining a specimen with intact mesocolic fascia, which envelope the lymphatic drainage of the tumor, is mandatory. The tumor around the splenic flexure is dominated by the origin of the inferior mesenteric artery 
A

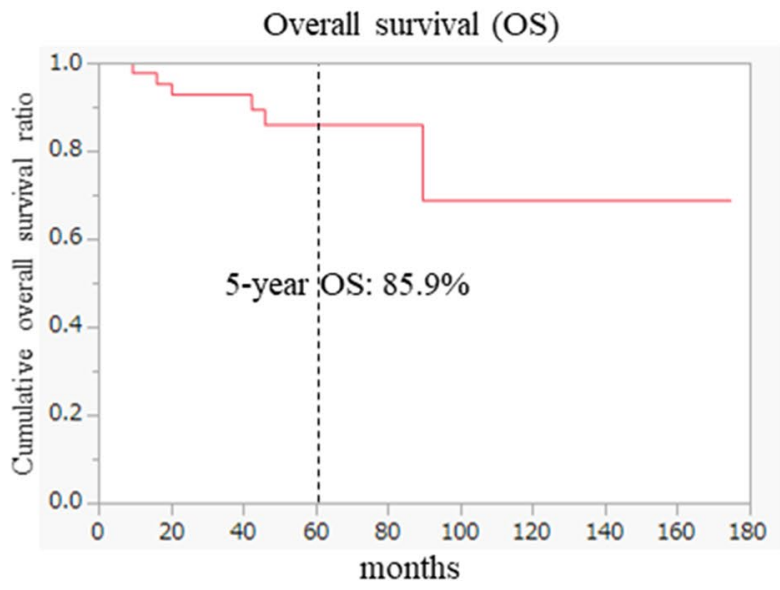

C

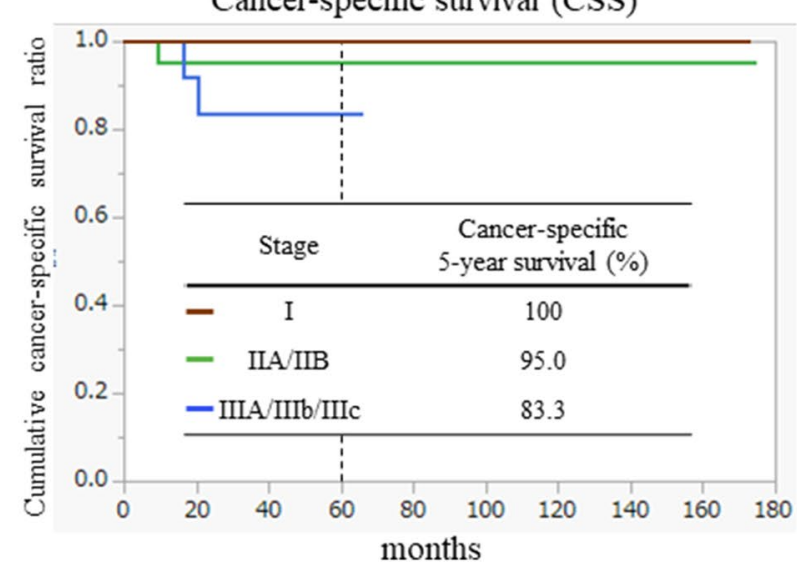

B

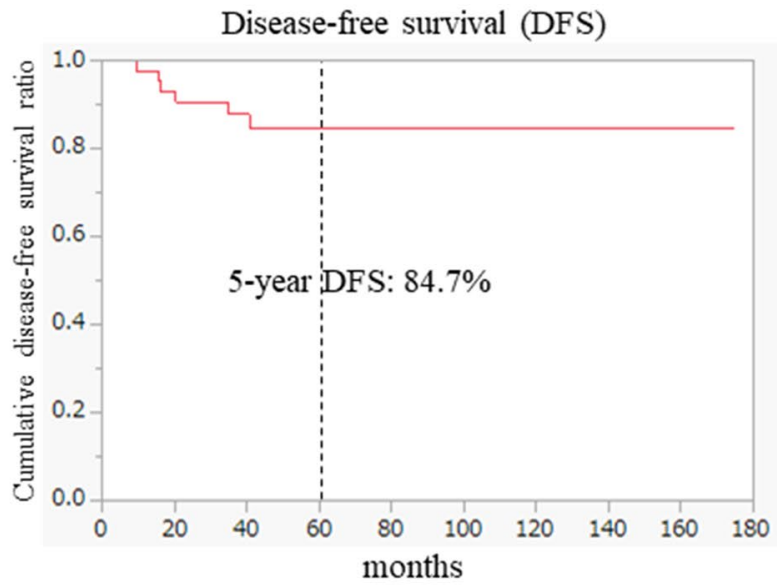

Fig. 2 Oncologic long-term outcomes. A Overall survival. B Disease-free survival. c Cancer-specific survival. The table shown in (C) indicates differences in cancer-specific survival according to disease Stage I to III

or the middle colic artery. Therefore, a variety of lymphatic drainage events along with the blood supply of the splenic flexure are observed. To determine the resection margin and the area for lymphadenectomy, we applied 3D CT angiography over a routine preoperative workup. Most tumors in the splenic flexure are supplied by the left colic artery originating from the inferior mesenteric artery. Griffiths performed colic vessel aortography on 71 patients. Of these patients, the percentage of blood supply to the splenic flexure from the left colic artery was $66 \%$ on aortograms [33]. In recent years, Fukuoka et al. [34] reported the classification of blood supply to the splenic flexure using CT angiography and colonography for 202 patients. They reported that $53.7 \%$ of the blood to the splenic flexure was supplied by the left colic artery. In our study, the percentage of blood supplied by the left colic artery was $81.6 \%$ (31/38) among patients who underwent CT angiography or contrast-enhanced CT. This ratio was similar to that in the report by Nakashima et al. [27], in which $89 \%$ of splenic flexure colon cancers were supplied through the left colic artery according to the operative records. Nakagoe et al. [35] described a similar study on 27 patients with splenic flexure colon cancer who underwent splenic flexure segment resection. They also reported no metastases at the root of the inferior mesenteric artery or the middle colic artery and concluded that the routine extended right hemicolectomy might not be necessary to cure splenic flexure colon cancer. As indicated in Fig. 1, most of the metastatic lymph nodes existed in the epicolic/ paracolic area, and no metastatic lymph nodes existed in the lymph nodes at the root of the inferior mesenteric artery or middle colic artery. Moreover, there was no case of lymph node recurrence during the follow-up period. Our indication for the surgical resection margin and lymphadenectomy was appropriate for splenic flexure colon cancer.

In recent years, various studies have described intraoperative laparoscopic real-time indocyanine green (ICG) fluorescence imaging using a near-infrared camera system to recognize the pathway of lymphatic drainage from the tumor $[30,36,37]$. This useful modality can detect the precise dissection area of the colic mesentery for CME. Although ICG is not a cancer-specific fluorophore, it can potentially detect lymph node metastasis. However, it is limited by the fact 


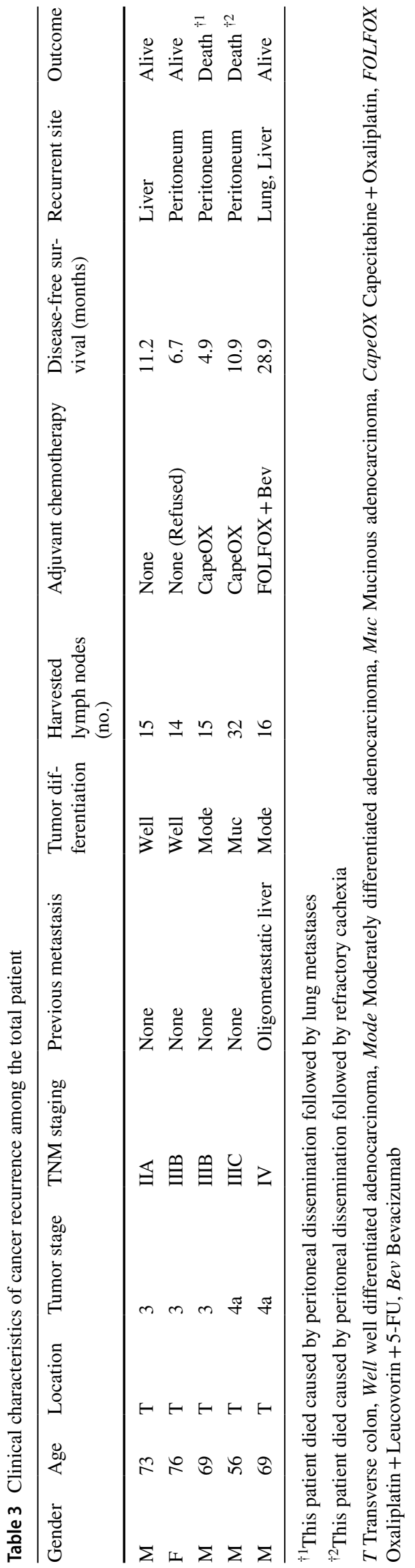

that it cannot detect the ICG spreading area, and it may alter the lymphatic flow. Regarding patient-specific limitations, if a patient is obese with a thick, fat mesentery, lymphatic spread cannot be observed during the procedure. Concerning cancer-specific limitations, ICG cannot enter the lymph node sinus in highly metastatic lymph nodes. As a result, ICG cannot be observed, or it may alter lymphatic flow from the tumor. Four of 57 patients with splenic flexure colon cancer who analyzed in our previous prospective study on the intraoperative detection of lymphatic flow and lymph nodes using ICG fluorescence imaging were included also in this study [38]. Three of these four patients who were pathologically diagnosed with stage $\mathrm{N} 1 \mathrm{a} / \mathrm{b}$ disease had ICG-positive lymph nodes along the left colic artery, middle colic artery, and left accessory aberrant colic artery (Fig. 3). In the other patient with metastatic lymph nodes and liver metastases, lymphatic flow and lymph nodes were not observed. ICG fluorescence imaging seems to be an informative modality to identify potentially metastatic lymph nodes for early colon cancer or clinically node-negative advanced colon cancer. If the cancer-specific agents that can be used to identify metastatic lymph nodes during surgery are developed, it will be possible to perform patient-specific or tumor-specific surgery in the near future.

Regarding the long-term follow-up, the 5-year overall survival and disease-free survival rates in patients with stage I-III disease were $85.9 \%$ and $84.7 \%$, respectively. However, more patients died of other diseases than cancer progression. The cancer-specific survival rate in this series was $92.7 \%$ (100\% in patients with stage I, $95 \%$ in patients with stage II, and $83.3 \%$ in patients with stage III disease). This result was similar to that reported in patients who underwent laparoscopy in JCOG 0404, a phase 3 RCT [7]. Moreover, Hohenberger et al. [8] were the first to describe CME with CVL for colon cancer surgery. They reported 5-year cancerrelated survival rates of $99.1 \%, 91.4 \%$, and $70.2 \%$ in patients with stage I, II and III disease, respectively, $4.4 \%$ of whom had splenic flexure colon cancer [8].

During the follow-up period, five patients (11.1\%) experienced recurrence, including three with peritoneal dissemination $(6.7 \%)$. From 2000 to 2020, six retrospective case studies or comparative studies on splenic flexure colon cancer were performed except in the case report or technical report (Table 5). The rate of local recurrences, such as the anastomotic recurrence, was $0.6-4.3 \%$. The rates of lymph node metastasis, peritoneal recurrence, and distant metastasis were $1.8-4.2 \%, 2.0-20.6 \%$, and 3.6-23.5\%, respectively. The patients' backgrounds (e.g., procedure and operative stage) in these studies were quite different. However, the 
Table 4 Patients' series of splenic flexure colon cancer or transverse and descending colon cancer in the literature

\begin{tabular}{|c|c|c|c|c|c|c|}
\hline $\begin{array}{l}\text { Akiyoshi et al. } \\
{[26]}\end{array}$ & $\begin{array}{l}\text { Nakshima et al. } \\
{[27]}\end{array}$ & Kim et al. [28] & $\begin{array}{l}\text { Yamagu- } \\
\text { chi et al. } \\
{[29]}\end{array}$ & $\begin{array}{l}\text { Watanabe et al. } \\
{[30]}\end{array}$ & $\begin{array}{l}\text { Toritani et al. } \\
{[31]}\end{array}$ & Blacale et al. [32] \\
\hline 260 & 33 & 33 & 958 & 31 & 33 & 112 \\
\hline 194 [95-405] & 209 [144-299] & 295 [255-362.5] & - & $206[-]$ & 179 [137-195] & $155.2[-]$ \\
\hline $18[0-740]$ & $15[0-1150]$ & - & - & $52.5[-]$ & $30[10-50]$ & - \\
\hline 3.5 & 6.1 & 9.1 & 3.2 & 0 & 0 & 3.6 \\
\hline 0.8 & 3.0 & 6.1 & 4.5 & 0 & 0 & 5.4 \\
\hline 6.9 & 6.0 & 18.2 & 15.8 & 9.7 & 6.1 & 18.8 \\
\hline 0.8 & 3.0 & 0 & 1.0 & 0 & 0 & 3.6 \\
\hline
\end{tabular}

results of the latter studies (from 2015 to 2020), including laparoscopic case studies, showed a similar incidence of recurrence to that in the present study, though the mechanism of these patterns of recurrence was unclear. To identify the mechanism involved, we should examine a large number of case registries on splenic flexure colon cancer.

The present study had some limitations. First, it was a retrospective study, and the case number was small. Second, this study was historically reviewed; it was not a comparative study with open surgery. Third, some technical errors and biases could not be ignored. For example, we did not estimate the injury of the mesentery, 'incomplete CME', in each case.

\section{Conclusion}

In conclusion, laparoscopic CME with CVL for splenic flexure colon cancer appears to be oncologically safe and feasible based on the short- and long-term outcomes reported in our study. However, this procedure is challenging because of the understanding of surgical anatomy and the necessity of surgeon's skill to balance the avoidance of other organ injury and the curability of cancer. The appropriate indications must be established with more case registries because our experience is limited. 


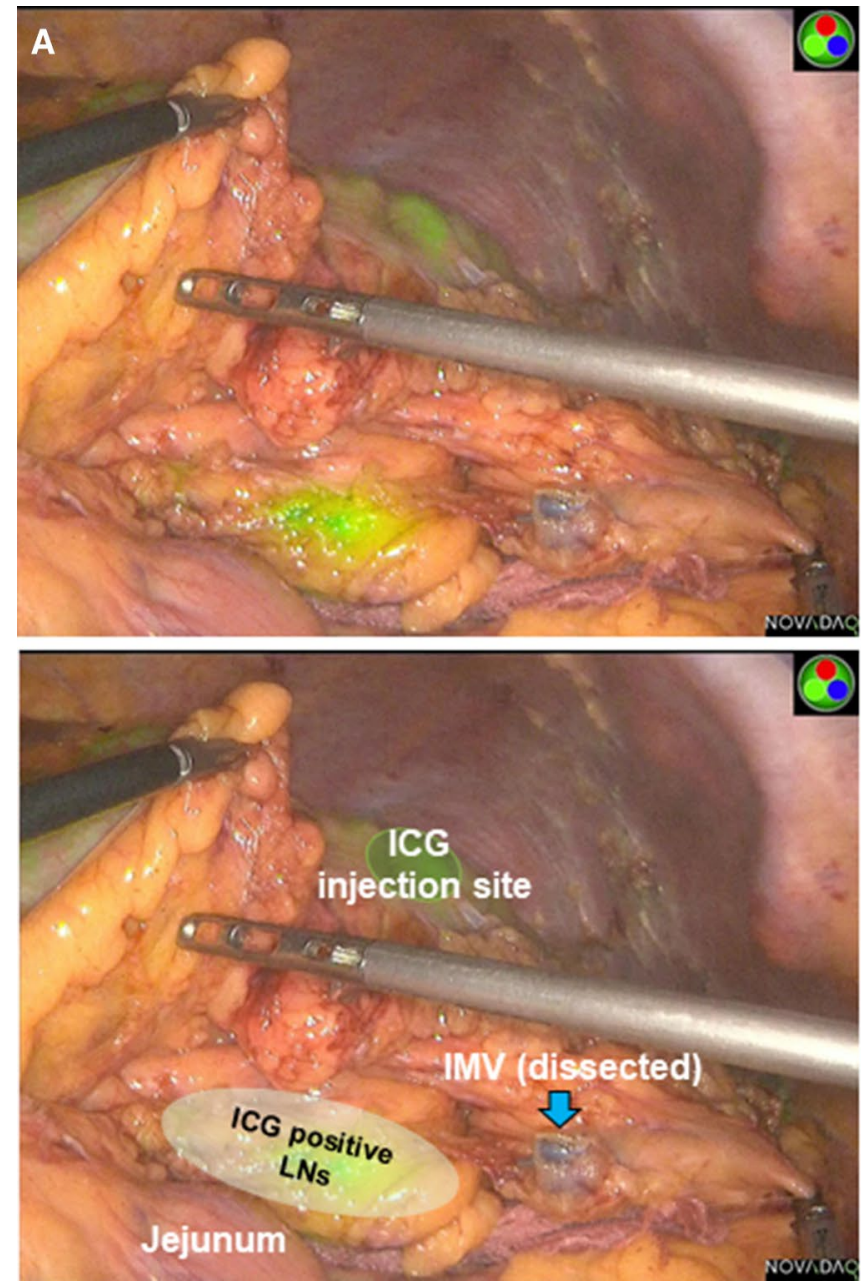

Fig. 3 Intraoperative ICG fluorescence imaging. (e.g., ICG-positive lymph nodes identified around the left accessory aberrant artery). A Distant view. B Close view. The names of the structures are shown
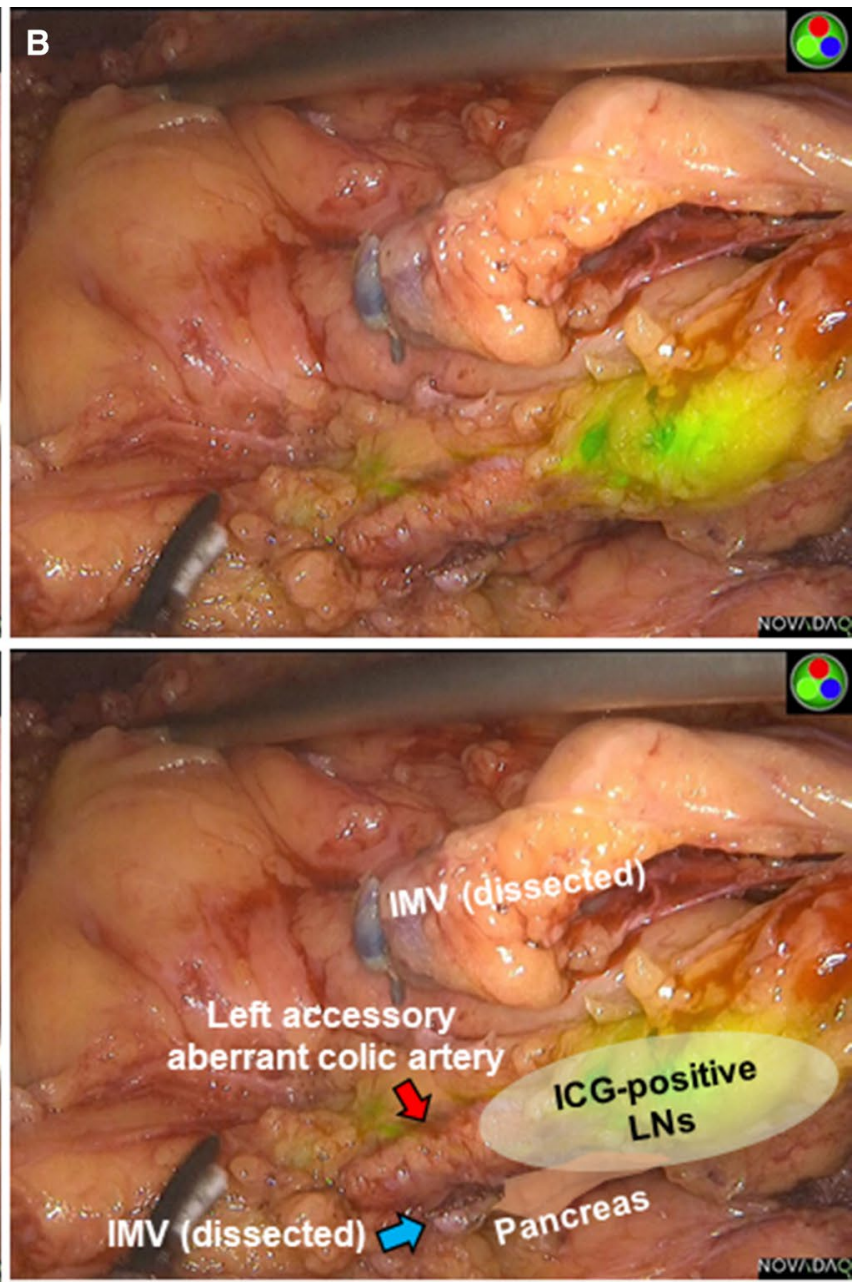

in the figures below. ICG indocyanine green, $I M V$ inferior mesenteric vein, $L N s$ lymph nodes

Table 5 Recurrent cases of splenic flexure colon cancer in the literature

\begin{tabular}{|c|c|c|c|c|c|c|c|}
\hline & $\begin{array}{l}\text { Nakagoe et al. } \\
\text { [39] }\end{array}$ & Kim et al. [24] & $\begin{array}{l}\text { Pisani Cer- } \\
\text { etti et al. } \\
{[15]}\end{array}$ & Kim et al. [28] & Rega et al. [16] & Bracale et al. [32] & Current study \\
\hline $\begin{array}{l}\text { Number of } \\
\text { patients }\end{array}$ & 34 & 167 & 23 & 51 & 57 & 112 & 45 \\
\hline Open/Lap (no.) & Open & Open & Lap & $\begin{array}{l}\text { Open (18)/Lap } \\
\text { (33) }\end{array}$ & $\begin{array}{l}\text { Open (47)/Lap } \\
\text { (10) }\end{array}$ & Lap & Lap \\
\hline $\begin{array}{l}\text { Follow-up } \\
\text { (months) }\end{array}$ & 30 & 82 & 33 & 59 & 42 & 43 & 49 \\
\hline $\begin{array}{l}\text { Local recurrence } \\
(\%)\end{array}$ & - & $1(0.6)$ & $1(4.3)$ & $1(2.0)$ & $2(3.5)$ & $4(3.6)$ & 0 \\
\hline $\begin{array}{l}\text { Lymph node } \\
\text { metastasis (\%) }\end{array}$ & - & $7(4.2)$ & - & $1(2.0)$ & - & $2(1.8)$ & 0 \\
\hline $\begin{array}{l}\text { Peritoneal dis- } \\
\text { semination (\%) }\end{array}$ & $7(20.6)$ & $16(9.6)$ & - & $1(2.0)$ & - & $5^{*}(4.5)$ & $3(6.7)$ \\
\hline $\begin{array}{l}\text { Distant metastasis } \\
(\%)\end{array}$ & $8(23.5)$ & $25(15.0)$ & $1(4.3)$ & $3(5.9)$ & $12(21.1)$ & $4(3.6)$ & $2(4.4)$ \\
\hline
\end{tabular}

*Two cases of 5 peritoneal disseminations were observed simultaneously occurred lymph node metastasis and distant metastasis, respectively 
Funding None.

\section{Declarations}

Disclosures Drs. Kazuki Ueda, Koji Daito, Hokuto Ushijima, Yoshinori Yane, Yasumasa Yoshioka, Tadao Tokoro, Masayoshi Iwamoto, Toshiaki Wada, Yusuke Makutani, and Junichiro Kawamura have no conflict of interest or financial ties to disclose.

Open Access This article is licensed under a Creative Commons Attribution 4.0 International License, which permits use, sharing, adaptation, distribution and reproduction in any medium or format, as long as you give appropriate credit to the original author(s) and the source, provide a link to the Creative Commons licence, and indicate if changes were made. The images or other third party material in this article are included in the article's Creative Commons licence, unless indicated otherwise in a credit line to the material. If material is not included in the article's Creative Commons licence and your intended use is not permitted by statutory regulation or exceeds the permitted use, you will need to obtain permission directly from the copyright holder. To view a copy of this licence, visit http://creativecommons.org/licenses/by/4.0/.

\section{References}

1. Nelson H, Sargent DJ, Wieand HS, Fleshman J, Anvari M, Stryker SJ, Beart RW Jr, Hellinger M, Flanagan R Jr, Peters W, Ota D (2004) A comparison of laparoscopically assisted and open colectomy for colon cancer. N Engl J Med 350:2050-2059

2. Veldkamp R, Kuhry E, Hop WC, Jeekel J, Kazemier G, Bonjer HJ, Haglind E, Påhlman L, Cuesta MA, Msika S, Morino M, Lacy AM (2005) Laparoscopic surgery versus open surgery for colon cancer: short-term outcomes of a randomised trial. Lancet Oncol 6:477-484

3. Guillou PJ, Quirke P, Thorpe H, Walker J, Jayne DG, Smith AM, Heath RM, Brown JM (2005) Short-term endpoints of conventional versus laparoscopic-assisted surgery in patients with colorectal cancer (MRC CLASICC trial): multicentre, randomised controlled trial. Lancet 365:1718-1726

4. Bonjer HJ, Hop WC, Nelson H, Sargent DJ, Lacy AM, Castells A, Guillou PJ, Thorpe H, Brown J, Delgado S, Kuhrij E, Haglind E, Påhlman L (2007) Laparoscopically assisted vs open colectomy for colon cancer: a meta-analysis. Arch Surg 142:298-303

5. Kitano S, Inomata M, Sato A, Yoshimura K, Moriya Y (2005) Randomized controlled trial to evaluate laparoscopic surgery for colorectal cancer: Japan Clinical Oncology Group Study JCOG 0404. Jpn J Clin Oncol 35:475-477

6. Yamamoto S, Inomata M, Katayama H, Mizusawa J, Etoh T, Konishi F, Sugihara K, Watanabe M, Moriya Y, Kitano S (2014) Short-term surgical outcomes from a randomized controlled trial to evaluate laparoscopic and open D3 dissection for stage II/III colon cancer: Japan Clinical Oncology Group Study JCOG 0404. Ann Surg 260:23-30

7. Kitano S, Inomata M, Mizusawa J, Katayama H, Watanabe M, Yamamoto S, Ito M, Saito S, Fujii S, Konishi F, Saida Y, Hasegawa H, Akagi T, Sugihara K, Yamaguchi T, Masaki T, Fukunaga Y, Murata K, Okajima M, Moriya Y, Shimada Y (2017) Survival outcomes following laparoscopic versus open D3 dissection for stage II or III colon cancer (JCOG0404): a phase 3, randomised controlled trial. Lancet Gastroenterol Hepatol 2:261-268

8. Hohenberger W, Weber K, Matzel K, Papadopoulos T, Merkel S (2009) Standardized surgery for colonic cancer: complete mesocolic excision and central ligation--technical notes and outcome. Colorectal Dis 11:354-364; discussion 364-355

9. West NP, Hohenberger W, Weber K, Perrakis A, Finan PJ, Quirke P (2010) Complete mesocolic excision with central vascular ligation produces an oncologically superior specimen compared with standard surgery for carcinoma of the colon. J Clin Oncol 28:272-278

10. Gouvas N, Agalianos C, Papaparaskeva K, Perrakis A, Hohenberger W, Xynos E (2016) Surgery along the embryological planes for colon cancer: a systematic review of complete mesocolic excision. Int J Colorectal Dis 31:1577-1594

11. Heald RJ, Husband EM, Ryall RD (1982) The mesorectum in rectal cancer surgery-the clue to pelvic recurrence? Br J Surg 69:613-616

12. West NP, Kobayashi H, Takahashi K, Perrakis A, Weber K, Hohenberger W, Sugihara K, Quirke P (2012) Understanding optimal colonic cancer surgery: comparison of Japanese D3 resection and European complete mesocolic excision with central vascular ligation. J Clin Oncol 30:1763-1769

13. Hashiguchi Y, Muro K, Saito Y, Ito Y, Ajioka Y, Hamaguchi T, Hasegawa K, Hotta K, Ishida H, Ishiguro M, Ishihara S, Kanemitsu Y, Kinugasa Y, Murofushi K, Nakajima TE, Oka S, Tanaka T, Taniguchi $\mathrm{H}$, Tsuji A, Uehara K, Ueno H, Yamanaka T, Yamazaki K, Yoshida M, Yoshino T, Itabashi M, Sakamaki K, Sano K, Shimada Y, Tanaka S, Uetake H, Yamaguchi S, Yamaguchi N, Kobayashi H, Matsuda K, Kotake K, Sugihara K (2020) Japanese Society for Cancer of the Colon and Rectum (JSCCR) guidelines 2019 for the treatment of colorectal cancer. Int J Clin Oncol 25:1-42

14. Jacobs M, Verdeja JC, Goldstein HS (1991) Minimally invasive colon resection (laparoscopic colectomy). Surg Laparosc Endosc 1:144-150

15. Pisani Ceretti A, Maroni N, Sacchi M, Bona S, Angiolini MR, Bianchi P, Opocher E, Montorsi M (2015) Laparoscopic colonic resection for splenic flexure cancer: our experience. BMC Gastroenterol 15:76

16. Rega D, Pace U, Scala D, Chiodini P, Granata V, Bucci A, Pecori B, Delrio P (2019) Treatment of splenic flexure colon cancer: a comparison of three different surgical procedures: experience of a high volume cancer center. Sci Rep 9:10953

17. Meagher AP, Woff BG (1994) Right hemicolectomy with a linear cutting stapler. Dis Colon Rectum 37:1043-1045

18. Yamamoto T, Keighley MRB (1999) Stapled functional end-to-end anastomosis in Crohn's disease. Surg Today 29:679-681

19. Venkatesh KS, Morrison N, Larson DM, Ramanujam P (1993) Triangulating stapling technique: An alternative approach to colorectal anastomosis. Dis Colon Rectum 36:73-76

20. Fukunaga Y, Higashino M, Tanimura S, Osugi H (2007) Triangulating stapling technique for reconstruction after colectomy. Hepatogastroenterol 74:414-417

21. Dindo D, Demartines N, Clavien PA (2004) Classification of surgical complications: a new proposal with evaluation in a cohort of 6336 patients and results of a survey. Ann Surg 240:205-213

22. Levien DH, Gibbons S, Begos D, Byrne DW (1991) Survival after resection of carcinoma of the splenic flexure. Dis Colon Rectum 34:401-403

23. Nakagoe T, Sawa T, Tsuji T, Jibiki M, Nanashima A, Yamaguchi H, Yasutake T, Ayabe H, Ishikawa H (2000) Carcinoma of the splenic flexure: multivariate analysis of predictive factors for clinicopathological characteristics and outcome after surgery. J Gastroenterol 35:528-535

24. Kim CW, Shin US, Yu CS, Kim JC (2010) Clinicopathologic characteristics, surgical treatment and outcomes for splenic flexure colon cancer. Cancer Res Treat 42:69-76

25. Martínez-Pérez A, Brunetti F, Vitali GC, Abdalla S, Ris F, de'Angelis N, (2017) Surgical treatment of colon cancer of the splenic flexure: a systematic review and meta-analysis. Surg Laparosc Endosc Percutan Tech 27:318-327 
26. Akiyoshi T, Kuroyanagi H, Oya M, Ueno M, Fujimoto Y, Konishi T, Yamaguchi T (2010) Factors affecting difficulty of laparoscopic surgery for left-sided colon cancer. Surg Endosc 24:2749-2754

27. Nakashima M, Akiyoshi T, Ueno M, Fukunaga Y, Nagayama S, Fujimoto Y, Konishi T, Noaki R, Yamakawa K, Nagasue Y, Kuroyanagi H, Yamaguchi T (2011) Colon cancer in the splenic flexure: comparison of short-term outcomes of laparoscopic and open colectomy. Surg Laparosc Endosc Percutan Tech 21:415-418

28. Kim MK, Lee IK, Kang WK, Cho HM, Kye BH, Jalloun HE, Kim JG (2017) Long-term oncologic outcomes of laparoscopic surgery for splenic flexure colon cancer are comparable to conventional open surgery. Ann Surg Treat Res 93:35-42

29. Yamaguchi S, Tashiro J, Araki R, Okuda J, Hanai T, Otsuka K, Saito S, Watanabe M, Sugihara K (2017) Laparoscopic versus open resection for transverse and descending colon cancer: short-term and long-term outcomes of a multicenter retrospective study of 1830 patients. Asian J Endosc Surg 10:268-275

30. Watanabe J, Ota M, Suwa Y, Ishibe A, Masui H, Nagahori K (2017) Evaluation of lymph flow patterns in splenic flexural colon cancers using laparoscopic real-time indocyanine green fluorescence imaging. Int J Colorectal Dis 32:201-207

31. Toritani K, Watanabe J, Nakagawa K, Suwa Y, Suwa H, Ishibe A, Ota M, Fujii S, Kunisaki C, Endo I (2019) Randomized controlled trial to evaluate laparoscopic versus open surgery in transverse and descending colon cancer patients. Int J Colorectal Dis 34:1211-1220

32. Bracale U, Merola G, Pignata G, Corcione F, Pirozzi F, Cuccurullo D, De Palma GD, Cassinotti E, Sciuto A, Boni L (2020) Laparoscopic resection with complete mesocolic excision for splenic flexure cancer: long-term follow-up data from a multicenter retrospective study. Surg Endosc 34:2954-2962

33. Griffiths JD (1956) Surgical anatomy of the blood supply of the distal colon. Ann R Coll Surg Engl 19:241-256
34. Fukuoka A, Sasaki T, Tsukikawa S, Miyajima N, Ostubo T (2017) Evaluating distribution of the left branch of the middle colic artery and the left colic artery by CT angiography and colonography to classify blood supply to the splenic flexure. Asian J Endosc Surg 10:148-153

35. Nakagoe T, Sawai T, Tsuji T, Jibiki M, Ohbatake M, Nanashima A, Yamaguchi H, Yasutake T, Kurosaki N, Ayabe H, Ishikawa H (2001) Surgical treatment and subsequent outcome of patients with carcinoma of the splenic flexure. Surg Today 31:204-209

36. Nishigori N, Koyama F, Nakagawa T, Nakamura S, Ueda T, Inoue T, Kawasaki K, Obara S, Nakamoto T, Fujii H, Nakajima Y (2016) Visualization of lymph/blood flow in laparoscopic colorectal cancer surgery by ICG fluorescence imaging (Lap-IGFI). Ann Surg Oncol 23(Suppl 2):S266-S274

37. Ozawa Y, Murakami M, Watanabe M, Yoshizawa S, Goto S, Otsuka K, Aoki T (2016) Preoperative colonic cancer tattooing using the near-infrared fluorescence laparoscopic imaging system. Asian J Endosc Surg 9:340-343

38. Ushijima H, Kawamura J, Ueda K, Yane Y, Yoshioka Y, Daito K, Tokoro T, Hida J, Okuno K (2020) Visualization of lymphatic flow in laparoscopic colon cancer surgery using indocyanine green fluorescence imaging. Sci Rep. https://doi.org/10.1038/s41598-02071215-3,Aug31,2020

39. Nakagoe T, Sawai T, Tsuji T, Jibiki M, Nakashima A, Yamaguti H, Yasutake T, Ayabe H, Ishikawa H (2000) Carcinoma of the splenic flexure: multivariate analysis of predictive factors for clinicopathological characteristics and outcome after surgery. J Gastroenterol 35:528-535

Publisher's Note Springer Nature remains neutral with regard to jurisdictional claims in published maps and institutional affiliations. 